DE

M E D I C I N A

T R O P I C A L

$\mathrm{DE}$

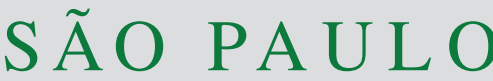

JOURNAL OF THE SÃO PAULO INSTITUTE OF TROPICAL MEDICINE

${ }^{1}$ Universidade Federal do Maranhão, Programa de Pós-Graduação em Biodiversidade e Biotecnologia da Amazônia Legal (Rede Bionorte), São Luís, Maranhão, Brazil

${ }^{2}$ Universidade de São Paulo, Faculdade de Medicina de Ribeirão Preto, Programa de Pós-Graduação em Saúde da Criança e do Adolescente, Ribeirão Preto, São Paulo, Brazil

${ }^{3}$ Universidade Federal do Maranhão, Departamento de Saúde Pública, São Luís, Maranhão, Brazil

${ }^{4}$ Universidade Federal do Maranhão, Programa de Pós-Graduação em Saúde e Tecnologia, Imperatriz, Maranhão, Brazil

${ }^{5}$ Universidade de Brasília, Instituto de Ciências Biológicas, Brasília, Distrito Federal, Brazil

Correspondence to: Márcia Cristina Gonçalves Maciel

Universidade de Brasília, Instituto de Ciências Biológicas, Campus Universitário Darcy Ribeiro, CEP 70910-900, Brasília, DF, Brazil

Tel: +55 $6199557-2485$

E-mail: macielmcg@gmail.com

Received: 19 November 2020

Accepted: 11 March 2021

\section{Trend in infant mortality rate caused by sepsis in Brazil from 2009 to 2018}

\author{
Liliane dos Santos Rodrigues ${ }^{(1)}$, Livia dos Santos Rodrigues ${ }^{(1)}$ 2, Luciana \\ Cavalcante Costa ${ }^{\circledR 3}$, Guilherme Martins Gomes Fontoura ${ }^{(1)}$, Márcia Cristina \\ Gonçalves Maciel $^{\circledR 5}$
}

\section{ABSTRACT}

Sepsis is the organ dysfunction resulting from an infection associated with an unregulated host inflammatory response, which generates high mortality rates in Brazil. The aim of this stydy was to analyze the trend of early, late and post-neonatal mortality rates due to sepsis in Brazilian regions, from 2009 to 2018 . This is an ecological study of time series. The trend of infant mortality from sepsis was analyzed using the International Classification of Diseases (ICD10) according to the place of residence (North, Northeast, Southeast, South and Midwest). Death Certificate data were collected from the Mortality Information System database. The temporal trend was analyzed using the Prais-Winsten estimate, interpreted as increasing, decreasing or stable, through the dependent variable (logarithm of mortality rates) and interdependent variables (years of the historical series). The Stata 14.0 statistical software was used. There were 39,867 infant deaths due to sepsis (78.67\% for unspecified bacterial sepsis of the neonate ). Most of the children were male, had mixed ethnicity (black and white), were born preterm with low birth weight and most mothers were 20-34 years old. There were decreasing trends in mortality rates from 2009 to 2018: early neonatal, in the Southeast (-3.57\%), North $(-3.33 \%)$ and South $(-2.91 \%)$; late neonatal, in the South $(-4.12 \%)$, Southeast $(-4.53 \%)$, North $(-4.55 \%)$ and Midwest (-6.21\%); and post-neonatal, in the Northeast (-1.84\%), North (-3.62\%), Southeast $(-3.83 \%)$ and Midwest $(-5.81 \%)$. The Northeast showed a stable trend in early and late neonatal mortality rates. It was concluded that most regions showed a decreasing trend in mortality rates from sepsis in all age components, despite regional differences.

KEYWORDS: Infant mortality. Time series studies. Sepsis.

\section{INTRODUCTION}

Sepsis is considered a serious health problem worldwide and one of the ten to causes of deaths ${ }^{1-3}$. Despite the fact that it occurs in any age group, children represent an extremely fragile group in the face of this syndrome ${ }^{2}$, especially in developing countries that are composed of a huge number of inhabitants ${ }^{3}$. This vulnerability can be observed by means of a sensitive indicator called the infant mortality coefficient, which takes into account the number of deaths of children under one year old for every thousand live births (LBs). Through this coefficient, it is possible to accurately assess in a given time and geographic space, socioeconomic and health care development characteristics ${ }^{4}$. The high susceptibility of children to sepsis has been attributed to their immature immune system ${ }^{5}$ leading newborns to present with a hyperinflammatory immune response ${ }^{6}$.

A systematic review, aiming to estimate the global burden and mortality from sepsis in neonates and children, observed that mortality ranged from $1 \%$ to $5 \%$ for 
sepsis and $9 \%$ to $20 \%$ for severe sepsis. Between the years 2016 and 2019, this syndrome was responsible for the death of $69.35 \%$ of neonates worldwide ${ }^{7}$. In Brazil, among the ten main causes of death in the country in 2015, bacterial infections in newborns ranked fourth, with a rate of 1.69 per thousand live births ${ }^{8}$.

Neonatal sepsis generates enormous expenses for the health system due to long-term hospitalizations (mainly in intensive care units - ICUs), highly complex and invasive procedures, and the great need for broad-spectrum antibiotics. In addition, due to the fact that neonates are morefragile, they have a greater chance of progressing to death ${ }^{4}$.

Time trend analysis are widely used strategies for disease surveillance and control actions. Knowing the temporal trend of sepsis in Brazil is essential for planning and implementing prevention and control actions ${ }^{9}$ and there are few studies with this temporal design addressing infant mortality from sepsis and all its components.

Knowing this scenario, it is possible to assist in the elaboration of public policies that lead to effective changes in the regional and national epidemiological scenario. Thus, considering the importance of the theme and the scarcity of studies focusing on this population group, this study aimed to analyze the trend in early neonatal, late neonatal and postneonatal mortality from sepsis, in the five Brazilian regions, from 2009 to 2018.

\section{MATERIALS AND METHODS}

This is an ecological time series study, in which the trend in infant mortality rates from sepsis as a basic cause was analyzed, according to the place of residence (North, Northeast, Southeast, South and Midwest), in the period from 2009 to 2018.

Data collection was carried out through the official information systems of the Department of Informatics from the Unified Health System (DATASUS) of the Ministry of Health. Death Certificates(DC) contained in the database of the Mortality Information System were consulted. (SIM) and the declaration of live births (DNV) in the Live Birth Information System (SINASC) were used as collection instruments.

According to the Instruction Manual for Completing the Death Certificate ${ }^{10}$, the basic cause can be conceptualized as "the disease or injury that started the chain of pathological events that led directly to death, or the circumstances of the accident or violence that produced the fatal injury". Mortality statistics are produced from the basic cause declared by the medical doctor responsible for filling out the Death Certificate $^{10}$.

The Death Certificate is the basic document of the SIM, printed in three pre-numbered and carbonless copies. It must be completed for all deaths (fetal and non-fetal), whether they occurred in health units, homes or other places. Its main objectives are to be the standard document for collecting data on mortality, which are used in the vital and epidemiological statistics of the country and also to be the skillful document for issuing the Death Certificate, drawn up by the Civil Registry Offices. Thus, in addition to their legal function, these data on deaths enable them to be used to understand the population's health situation and to promote actions for its improvement, therefore, data must be reliable $\mathrm{e}^{10,11}$.

The International Classification of Diseases - ICD-10 was used toidentify the following cases of sepsis:A02.1 (Salmonella septicemia), A40.0 (group A Streptococcus septicemia), A40.1 (group Streptococcus septicemia) B), A40.3 (Septicemia by Streptococcuspneumonia), A40.9 (Streptococcal septicemia, unspecified), A41.0 (Septicemia by Staphylococcus aureus), A41.1 (Septicemia by other specified staphylococci), A41.2 (Septicemiaby unspecified staphylococci), A41.3 (Septicemia by Haemophilusinfluenzae), A41.5(Septicemiaby othergramnegative microorganisms), A41.8(Otherspecified septicemia), A41.9 (Unspecified septicemia), A42.7 (Actinomycotic septicemia), B37.7 (Candida septicemia), P36.0 (Newborn septicemia due to group B streptococcus), P36.1 (Newborn septicemia due to other and unspecified streptococci), P36.2 (Septicemia of the newborn due to Staphylococcus aureus), P36.3 (Newborn septicemia due to other and unspecified staphylococci), P36.4 (Septicemia of the newborn due to Escherichia coli), P36.5 (Septicemia of the newborn due to anaerobes), P36.8 (Other septicemias bacterial infections of the newborn), P36.9 (unspecified bacterial septicemia of the newborn).

The aspects defined in 2005 by the International Pediatric Sepsis Consensus Conference (IPSCC), initially established the Systemic Inflammatory Response Syndrome (SIRS) as the presence of at least two of the following criteria, one of which must be changes in temperature or number of leukocytes, concomitant with the presence of a confirmed or suspected infectious condition. These criteria are: hyperthermia $\left(>38.5^{\circ} \mathrm{C}\right)$ or hypothermia $\left(<36{ }^{\circ} \mathrm{C}\right)$; tachycardia; tachypnea; and leukocytosis or leukopenia not secondary to chemotherapy, or the presence of young forms of neutrophils in peripheral blood ${ }^{12}$.

Children were characterized according to maternal age (up to 19, from 20 to 34 or 35 years old or more), gender (male or female), ethnicity/skin color of the child (white, black, mixed black and white, yellow or indigenous), gestational age (preterm, term or post-term) and birth weight (low weight when less than 2,500 g or not underweight - equal to or greater than 2,500 g).

Early neonatal mortality rates (up to six full days of life), late neonatal mortality (from seven to 27 full days of life) 
and post-neonatal mortality (from 28 to 364 full days of life) were calculated using the number of deaths as the numerator and in the denominator, the total number of live births in the population living in a given geographic space, in the year considered, multiplied by a thousand ${ }^{13}$. Children withignored age of death were excluded.

The temporal trend was analyzed using the Prais-Winsten regression model, the independent variable being the years of the historical series and the dependent variables being the logarithm of mortality rates. This method makes it possible to analyze whether the trends of the object of study will be increasing, decreasing or stationary/stable, in addition to quantifying the rates of annual variations. As it is a regression model in the presence of autocorrelation of errors, without the need to readjust the analyzed models, trend estimates tend to be more significant ${ }^{14}$. Thus, it was possible to assess the trend (increasing, decreasing or stable), as well as measuring the percentage of change in each time series. The trend was considered stable when the regression coefficient did not differ from zero $(p>0.05)$.
The analyzes were performed using the statistical software Stata (version 14.0, StataCorp, College Station, Texas, USA) and the results were presented through graphs and tables.

Only secondary and aggregated data of public domain and free access were used. Thus, the study was exempted from appreciation by the Research Ethics Committee, according to the National Health Council resolution $\mathrm{N}^{\circ} 466$, of December $12^{\text {th }}, 2012$.

\section{RESULTS}

In Brazil, 384,687 infant deaths were reported in the SIM. Of these, 39,867 (10.4\%) were due to sepsis. The rates of early neonatal mortality from sepsis, late neonatal and postneonatal showed, respectively, that the children were mostly male $(58.1 \%, 54.5 \%$ and $53.7 \%)$, of mixed ethnicity / skin color $(56 \% ; 51.3 \%$ and $50.6 \%)$, born preterm $(80.5 \%, 82.6 \%$ and $69.0 \%$ ) with low birth weight $(73.4 \%, 76.1 \%$ and $54.4 \%)$. Regarding the age group, most mothers were between 20 and 34 years old $(62.9 \%, 62.5 \%$ and $63.2 \%)$ (Table 1$)$.

Table 1 - Maternal and neonatal characteristics according to age components in the five Brazilian regions, from 2009 to 2018.

\begin{tabular}{|c|c|c|c|c|c|c|c|}
\hline \multirow{3}{*}{ Variables } & \multicolumn{6}{|c|}{ Mortality rate } & \multirow{3}{*}{ Total } \\
\hline & \multicolumn{2}{|c|}{ Early neonatal } & \multicolumn{2}{|c|}{ Late neonatal } & \multicolumn{2}{|c|}{ Post-neonatal } & \\
\hline & $\mathrm{N}$ & $\%$ & $\mathrm{~N}$ & $\%$ & $\mathrm{~N}$ & $\%$ & \\
\hline \multicolumn{8}{|l|}{ Maternal age* } \\
\hline$<20$ & 3,409 & 24.5 & 2,876 & 23.7 & 1,922 & 22.2 & 8,207 \\
\hline 20 to 34 & 8,763 & 62.9 & 7,584 & 62.5 & 5,466 & 63.2 & 21,813 \\
\hline $35+$ & 1,767 & 12.7 & 1,670 & 13.8 & 1,263 & 14.6 & 4,700 \\
\hline Total & 13,939 & 100.0 & 12,130 & 100.0 & 8,651 & 100.0 & 34,720 \\
\hline \multicolumn{8}{|l|}{ Gender* } \\
\hline Male & 9,112 & 58.1 & 7,391 & 54.5 & 5,666 & 53.7 & 22,169 \\
\hline Female & 6,560 & 41.9 & 6,175 & 45.5 & 4,880 & 46.3 & 17,615 \\
\hline Total & 15,672 & 100.0 & 13,566 & 100.0 & 10,546 & 100.0 & 39,784 \\
\hline \multicolumn{8}{|l|}{ Skin color/ethnicity* } \\
\hline White & 5,660 & 40.9 & 5,465 & 45.4 & 4,230 & 44.7 & 15,355 \\
\hline Black & 294 & 2.1 & 281 & 2.3 & 267 & 2.8 & 842 \\
\hline Yellow & 18 & 0.1 & 16 & 0.1 & 20 & 0.2 & 54 \\
\hline Mixed (black and white) & 7,747 & 56.0 & 6,174 & 51.3 & 4,790 & 50.6 & 18,711 \\
\hline Indigenous & 126 & 0.9 & 96 & 0.8 & 164 & 1.7 & 386 \\
\hline Total & 13,845 & 100.0 & 12,032 & 100.0 & 9,471 & 100.0 & 35,348 \\
\hline \multicolumn{8}{|l|}{ Gestational age* } \\
\hline Pre-term & 11,113 & 80.5 & 9,933 & 82.6 & 5,552 & 69.0 & 26,598 \\
\hline Term & 2,630 & 19.1 & 2,051 & 17.0 & 2,395 & 29.7 & 7,076 \\
\hline Post-term & 54 & 0.4 & 47 & 0.4 & 103 & 1.3 & 204 \\
\hline Total & 13,797 & 100.0 & 12,031 & 100.0 & 8,050 & 100.0 & 33,878 \\
\hline \multicolumn{8}{|l|}{ Birth weight* } \\
\hline Low weight & 11,524 & 73.4 & 10,344 & 76.1 & 5,738 & 54.4 & 27,596 \\
\hline Not low weight & 4,181 & 26.6 & 3,246 & 23.9 & 4,811 & 45.6 & 12,238 \\
\hline Total & 15,705 & 100.0 & 13,580 & 100.0 & 10,549 & 100.0 & 39,834 \\
\hline
\end{tabular}

${ }^{\star}$ Ignored values due to lack of data filling 
According to ICD-10, unspecified bacterial septicemia of the newborn (78.67\%) was the most representative cause of death, followed by unspecified septicemia (16.34\%), as shown in Table 2.

From 2009 to 2018, the infant mortality rate from sepsis in all age components was higher in the North region. It was also observed that the lowest infant mortality rates due to sepsis occurred in the South (Table 3).

Analyzing the trend of early neonatal mortality rates due to sepsis in the period from 2009 to 2018 , it was observed that these parameters were decreasing in the Southeast, North and South regions. As for the trend of late neonatal mortality from sepsis, it was noted that they were decreasing in the South, Southeast, North and Midwest regions. The Northeast region showed a steady trend in early and late neonatal age components (Figure 1 and Table 4).

In the post-neonatal age component, with the exception of the South region, which showed a stable trend, all other regions showed a decreasing trend in infant mortality from sepsis (Figure 1 and Table 4).

\section{DISCUSSION}

The results of this study showed that the infant mortality rate due to sepsis was higher in the North, compared to other regions in Brazil. With the exception of the Northeast region, which showed a stable trend in early and late neonatal mortality from sepsis, the Midwest regarding the early neonatal age component and the South with respect to the post-neonatal age component, all other regions showed a decreasing trend. Despite the fact that this reduction and stability are positive points, the high number of deaths resulting from this syndrome in children is a warning that measures must be taken.

It was also found that sepsis represented $10.4 \%$ of the causes of death in children, a percentage similar to that found in the literature. In 2017, there was a worldwide estimate of 2.9 million (95\% UI 2.6-3.2) of sepsis-related deaths among children under five years of age ${ }^{15}$. Conducted in 2015, in 26 countries, the SPROUT study (Sepsis Prevalence, Outcomes, and Therapies), covering 6,925 children hospitalized in 128 pediatric intensive care units (PICU), found a prevalence of severe sepsis of $8.2 \%$, with a wide variation among continents: $6.2 \%$ in Europe, $16.3 \%$ in South America and $23.1 \%$ in Africa $(\mathrm{p}<0.001)^{16,17}$. The collaborative EUCLIDS (European Childhood Lifethreatening Infectious Disease Study), a prospective, multicenter, large-scale cohort, included 795 children hospitalized with community sepsis in 52 PICUs in seven European countries, finding a mortality rate of $6 \%$, reaching $10 \%$ in the presence of septic shock ${ }^{18}$.

Table 2 - Causes of death and microorganisms identified according to ICD-10 in the five Brazilian regions, from 2009 to 2018.

\begin{tabular}{|c|c|c|c|}
\hline ICD-10 & Basic cause & $\mathrm{N}$ & $\%$ \\
\hline$\overline{\mathrm{A} 021}$ & Salmonella septicemia & 3 & 0.01 \\
\hline A400 & Group A Streptococcus septicemia & 1 & 0.00 \\
\hline A401 & Group B Streptococcus septicemia & 2 & 0.01 \\
\hline A403 & Septicemia by Streptococcus pneumonia & 9 & 0.02 \\
\hline A409 & Streptococcal septicemia. unspecified & 15 & 0.04 \\
\hline A410 & Staphylococcus aureus septicemia & 12 & 0.03 \\
\hline A411 & Septicemia by other specified staphylococci & 15 & 0.04 \\
\hline A412 & Unspecified staphylococcal septicemia & 52 & 0.13 \\
\hline A413 & Haemophilus influenzae septicemia & 4 & 0.01 \\
\hline A415 & Septicemia by other gram-negative microorganisms & 35 & 0.09 \\
\hline A418 & Other specified septicemias & 138 & 0.35 \\
\hline A419 & Unspecified septicemia & 6,514 & 16.34 \\
\hline A427 & Actinomycotic septicemia & 5 & 0.01 \\
\hline B377 & Candida Septicemia & 83 & 0.21 \\
\hline P360 & Newborn septicemia due to group B streptococcus & 146 & 0.37 \\
\hline P361 & Newborn septicemia due to other and unspecified streptococci & 513 & 1.29 \\
\hline P362 & Septicemia of the newborn due to Staphylococcus aureus & 48 & 0.12 \\
\hline P363 & Newborn septicemia due to other and unspecified staphylococci & 115 & 0.29 \\
\hline P364 & Septicemia of the newborn due to Escherichia coli & 26 & 0.07 \\
\hline P365 & Newborn septicemia due to anaerobes & 40 & 0.10 \\
\hline P368 & Other bacterial septicemias of the newborn & 729 & 1.83 \\
\hline P369 & Unspecified bacterial septicemia of the newborn & 31,360 & 78.67 \\
\hline Total & & 39,867 & 100.00 \\
\hline
\end{tabular}


Table 3 - Infant mortality rates due to sepsis according to age components in the five Brazilian regions, from 2009 to 2018.

\begin{tabular}{|c|c|c|c|c|c|c|c|c|c|c|}
\hline \multirow{2}{*}{ Brazilian regions } & \multicolumn{10}{|c|}{ Early neonatal mortality } \\
\hline & 2009 & 2010 & 2011 & 2012 & 2013 & 2014 & 2015 & 2016 & 2017 & 2018 \\
\hline North & 1.02 & 0.82 & 0.77 & 0.77 & 0.73 & 0.64 & 0.75 & 0.65 & 0.70 & 0.70 \\
\hline Northeast & 0.72 & 0.61 & 0.59 & 0.67 & 0.67 & 0.64 & 0.69 & 0.57 & 0.59 & 0.53 \\
\hline Southeast & 0.62 & 0.58 & 0.59 & 0.49 & 0.45 & 0.50 & 0.46 & 0.53 & 0.46 & 0.41 \\
\hline South & 0.35 & 0.29 & 0.35 & 0.36 & 0.30 & 0.30 & 0.31 & 0.25 & 0.29 & 0.26 \\
\hline \multirow[t]{2}{*}{ Midwest } & 0.54 & 0.38 & 0.47 & 0.38 & 0.59 & 0.44 & 0.50 & 0.49 & 0.42 & 0.48 \\
\hline & \multicolumn{10}{|c|}{ Late neonatal mortality } \\
\hline North & 0.78 & 0.65 & 0.60 & 0.55 & 0.59 & 0.60 & 0.48 & 0.51 & 0.50 & 0.47 \\
\hline Northeast & 0.60 & 0.47 & 0.53 & 0.56 & 0.55 & 0.50 & 0.51 & 0.55 & 0.52 & 0.41 \\
\hline Southeast & 0.61 & 0.52 & 0.53 & 0.49 & 0.45 & 0.39 & 0.41 & 0.40 & 0.43 & 0.38 \\
\hline South & 0.35 & 0.32 & 0.33 & 0.32 & 0.34 & 0.30 & 0.29 & 0.26 & 0.22 & 0.25 \\
\hline \multirow[t]{2}{*}{ Midwest } & 0.51 & 0.47 & 0.54 & 0.46 & 0.41 & 0.40 & 0.43 & 0.35 & 0.31 & 0.28 \\
\hline & \multicolumn{10}{|c|}{ Post-neonatal mortality } \\
\hline North & 0.56 & 0.60 & 0.63 & 0.56 & 0.61 & 0.55 & 0.42 & 0.55 & 0.47 & 0.42 \\
\hline Northeast & 0.48 & 0.43 & 0.47 & 0.47 & 0.45 & 0.41 & 0.41 & 0.49 & 0.39 & 0.37 \\
\hline Southeast & 0.42 & 0.37 & 0.35 & 0.34 & 0.36 & 0.29 & 0.31 & 0.28 & 0.29 & 0.30 \\
\hline South & 0.20 & 0.20 & 0.25 & 0.24 & 0.23 & 0.22 & 0.18 & 0.14 & 0.16 & 0.14 \\
\hline Midwest & 0.33 & 0.36 & 0.32 & 0.31 & 0.28 & 0.24 & 0.28 & 0.22 & 0.20 & 0.26 \\
\hline
\end{tabular}

Regarding the trend, the study developed by Mangia et al. ${ }^{19}$ on hospitalizations of children and adolescents due to bacterial sepsis, based on records from the SUS Hospital Information System, from 1992 to 2006, also showed that the mortality rate among children under one year of age decreased from $24.82 \%$ to $21.92 \%$ ( $\mathrm{p}=$ 0.023 ) in 14 years. This decrease, as well as that found in this study, can be explained in part by the implementation of the Millennium Development Goals (MDGs), in which several countries, including Brazil, have pledged to reduce child mortality since $1990^{20,21}$.

Mangia et al. ${ }^{19}$ also observed that mortality rates in children under one year of age differed among Brazilian regions. Taking into account the Child Development Index (CDI) and the Human Development Index (HDI) by region, mortality rates in the North (IDI $=0.56$; HDI $=0.76$ ) was $25.5 \%$, in the Northeast $(\mathrm{IDI}=0.56$; HDI $=0.72) 30.2 \%$ and in the Midwest $(\mathrm{IDI}=0.70$; HDI $=0.81) 27.1 \%$. These were almost three times higher than in the South (IDI $=0.73$; HDI $=0.83$ ) with a mortality rate of $10.7 \%$. Thus, these lower rates in the South may be the result of the beneficial influence of the high socioeconomic level, which reflects in better health conditions for the population of this region, compared to others.

The improvement in indicators of severe pediatric sepsis and septic shock can be attributed to several factors such as the implementation worldwide of guidelines for coping with sepsis, such as the Surviving Sepsis Campaign, launched in
2004 and revised in 2008, 2012 and 2017; advances in public health actions (universal and free access to immunization, programs to combat malnutrition, preventinfectious diseases and encourage the rational use of antimicrobials) and improvements in hospital and PICU care c2-25. $^{2}$.

Thus, despite the regional socioeconomic differences that can have a decisive impact, when comparing, for example, the North and South regions of the country, the decrease in sepsis mortality rates in Brazil could be explained by the reasons mentioned above, in addition to policies, programs and strategies such as the promotion and encouragement of breastfeeding, Integrated Care for Childhood Illnesses, the strengthening of Primary Health Care, especially the expansion of the Family Health Strategy.

Regarding microorganisms, the rate of detection of pathogens found in other studies ranged from 30 to $65 \%{ }^{17,18,26,27}$. Weiss et al. ${ }^{17}$ observed that $65.4 \%$ of patients had an isolated infectious organism. Of these, they showed a similar distribution between infections by Gram-positive bacteria (26.5\%; 95\% CI 22.9-30.3\%) and Gram-negative (27.9\%; 95\% CI, 24.2-31.8\%) (Staphylococcus aureus being the most commonly isolated), and among fungi, mainly Candida species, were isolated in $13.4 \%$ of cases. Boeddha et al. ${ }^{18}$ observed that, of the 795 patients admitted with sepsis, 367 (46\%) had no confirmed bacterial etiology. Of the confirmed cases, Neisseria meningitidis was the most common pathogen (31\%), followed by Streptococcus pneumoniae $(\mathrm{n}=18 \%)$. 
Early neonatal mortality from sepsis
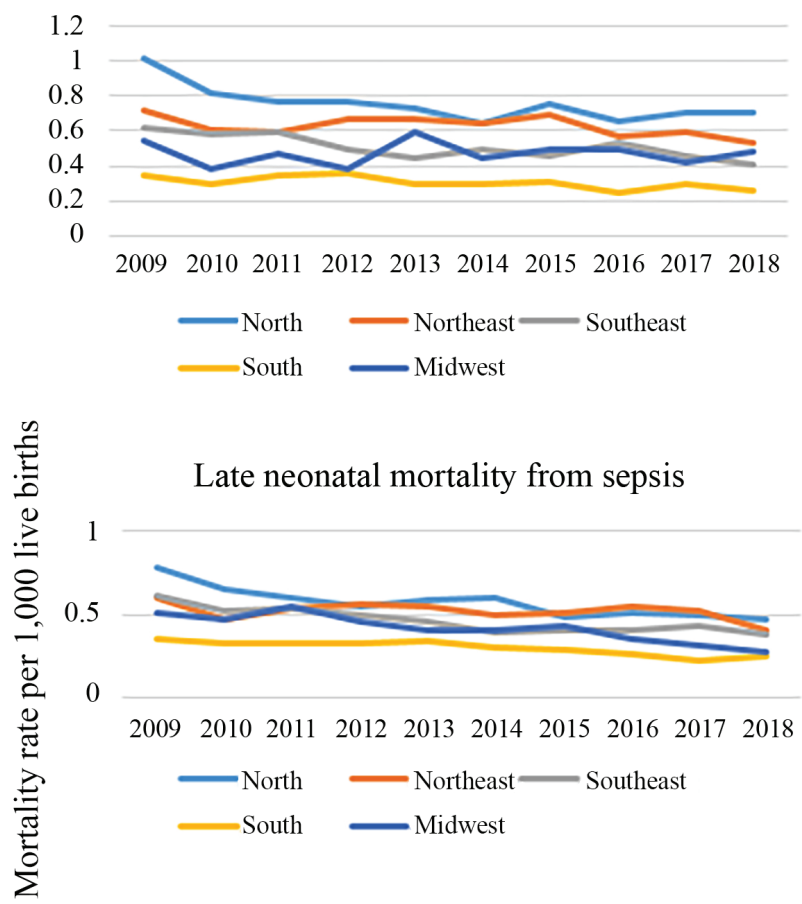

Post-neonatal mortality from sepsis

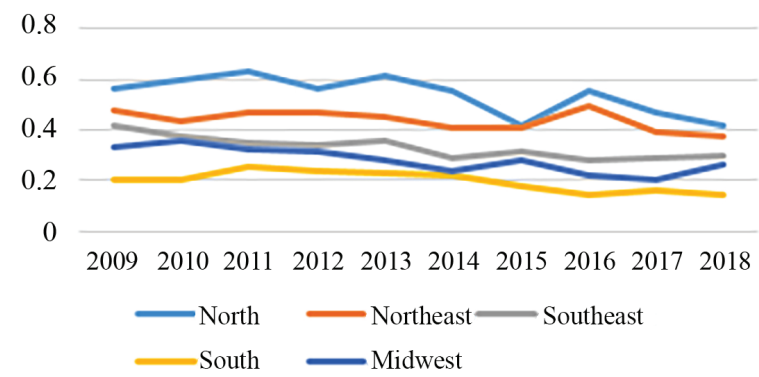

Figure 1 - Temporal distribution of early neonatal, late neonatal and post-neonatal mortality rates from sepsis in Brazilian regions, 2019-2018.

However, the present study found that $16.34 \%$ had unspecified septicemia and $78.67 \%$ unspecified bacterial septicemia of the newborn, which represents a high proportion of unspecified pathogens. Studies carried out in Jundiai, Sao Paulo State ${ }^{28}$ and Rio de Janeiro city, Rio de Janeiro State ${ }^{29}$ also did not identify the main infectious agent of deaths from sepsis, since in most ICDs, the infectious agent was not specified, totaling $58.7 \%$ and $95.1 \%$, respectively, of DOs classified as "Unspecified septicemia". For Elizeu et al. ${ }^{28}$, this could be justified by the fact that there is no requirement for the identification of the infectious agent in the definition of sepsis prior to the year 2016, according to the Latin American Sepsis Institute ${ }^{30}$, therefore applicable to this study, since the greater part of the historical series studied is concentrated in years prior to the current definition.
Results similar to those presented here were described by Liang et al. ${ }^{31}$. The researchers assessed clinical risk factors for mortality in infants under 12 months of age hospitalized for sepsis or serious infections, and it was observed that among neonates the rates were very high, ranging from 14.6 to 36 . $0 \%$ of patients, with prematurity and low birth weight being significantly associated with mortality.

In general, the main risk factors that are related to neonatal sepsis are: NICU (Neonatal Intensive Care Unit) hospitalization, due to the use of invasive procedures and possible contamination in the hospital environment; birth, gestational age and maternal conditions ${ }^{32}$. Among the factors that lead to the development of late sepsis, the following stand out: the use of catheters, venous punctures, mechanical ventilation, surgical interventions, inadequate hospital environment and inadequate hygiene of health professionals $^{33}$. And for early sepsis the factors are, among others: chorioamnionitis, maternal colonization by group $\mathrm{B}$ hemolytic beta streptococcus, premature rupture ( $<37$ weeks) and/ or prolonged rupture of membranes $(>18 \mathrm{~h})$, maternal urinary tract infection ${ }^{34}$.

Children who are in the context mentioned above have a more vulnerable immune system ${ }^{35}$, which favors the entry, establishment and proliferation of pathogenic microorganisms that can lead the individual to sepsis very quickly and intensely. For this reason, it is vitally important that early diagnosis and treatment are performed, in order to reduce the mortality rates from sepsis. This fact was confirmed by Alves et al. ${ }^{4}$, who showed the essential role of performing prenatal care as a way to prevent the onset or aggravation of possible diseases that affect the mother and the fetus during pregnancy.

This research presented limitations due to the use of secondary data available in the public domain, in addition to the possibility of underreported data, suggesting that mortality rates may be higher than those hereby presented, because despite the annual increase in coverage, SIM faces obstacles to improve the quality of its data, mainly due to insufficient completion of the Death Certificate(DC) ${ }^{10}$ and of the correct cause of death in terms of sequence. When sepsis is confirmed as the basic cause of death, the diagnosis and its specificity are lost, conditioning the loss of information to its origin. One of the main reasons for a large number of unspecified causes of death may be the filling of the chain of events on the Death Certificate. Therefore, actions taken to reduce these problems include investigating the conditions related to deaths in health facilities and training doctors on how to correctly complete the $\mathrm{DC}^{36}$.

However, the Mortality Information System (MIS) is an official system with consistent information used extensively in scientific research that generates important information 
Table 4 - Trend in infant mortality from sepsis according to age components in the five Brazilian regions, from 2009 to 2018.

\begin{tabular}{|c|c|c|c|c|c|}
\hline \multirow{2}{*}{ Brazilian regions } & \multicolumn{5}{|c|}{ Early neonatal mortality } \\
\hline & Coefficient & P-value* & Rate of change (\%) & Trend ${ }^{\star \star}$ & Coefficient \\
\hline North & -0.0147 & 0.008 & -3.33 & $-5.48:-1.12$ & Descending \\
\hline Northeast & -0.0085 & 0.074 & - & - & Stable \\
\hline Southeast & -0.0158 & 0.004 & -3.57 & $-5.57:-1.53$ & Descending \\
\hline South & -0.0128 & 0.005 & -2.91 & $-4.60:-1.20$ & Descending \\
\hline \multirow[t]{2}{*}{ Midwest } & 0.0024 & 0.554 & - & - & Stable \\
\hline & \multicolumn{5}{|c|}{ Late neonatal mortality } \\
\hline North & -0.0202 & $<0.001$ & -4.55 & $-6.14:-2.93$ & Descending \\
\hline Northeast & -0.0061 & 0.139 & - & - & Stable \\
\hline Southeast & -0.0201 & 0.001 & -4.53 & $-6.47:-2.55$ & Descending \\
\hline South & -0.0183 & 0.002 & -4.12 & $-6.20:-2.00$ & Descending \\
\hline \multirow[t]{2}{*}{ Midwest } & -0.0279 & $<0.001$ & -6.21 & $-8.25:-4.13$ & Descending \\
\hline & \multicolumn{5}{|c|}{ Post-neonatal mortality } \\
\hline North & -0.0160 & 0.004 & -3.62 & $-5.63:-1.52$ & Descending \\
\hline Northeast & -0.0080 & 0.030 & -1.84 & $-3.43:-0.22$ & Descending \\
\hline Southeast & -0.0170 & $<0.001$ & -3.83 & $-5.11:-2.54$ & Descending \\
\hline South & -0.0207 & 0.070 & - & - & Stable \\
\hline Midwest & -0.0260 & $<0.001$ & -5.81 & $-7.22:-4.37$ & Descending \\
\hline
\end{tabular}

*Significantly different from zero $(p<0.05) ;{ }^{* *}$ Trends were classified as increasing $(p \leq 0.05$ and positive regression coefficient $)$, decreasing $(p \leq 0.05$ and negative regression coefficient) and stable $(p>0.05)$.

to assist in the development of public policies that lead to effective changes in the epidemiological scenario at the regional level and even at the national one .

Most regions showed a decreasing trend in mortality from sepsis in all age components. However, they still have a high number of deaths, which indicates that preventive measures and alternative forms of treatment should be sought to reduce them. In addition, it is worth mentioning that the dissemination of this theme can provide new studies in order to promote the quality of patients' life, increase in the survival rate which would lead to a shorter hospital stay and the consequent reduction in public hospital spending, a great contribution to improving the health of the population.

\section{REFERENCES}

1. VincentJL, Marshall JC, Namendys-Silva SA, François B, MartinLoeches I, Lipman J, et al. Assessment of the worldwide burden of critical illness: the Intensive Care Over Nations (ICON) audit. Lancet Respir Med. 2014;2:380-6.

2. Colón DF, Wanderley CW, Franchin M, Silva CM, Hiroki CH, Castanheira FV, et al. Neutrophil extracellular traps (NETs) exacerbate severity of infant sepsis. Crit Care. 2019;23:113.

3. Randolph AG, McCulloh RJ. Pediatric sepsis: important considerations for diagnosing and managing severe infections in infants, children, and adolescents. Virulence. 2014;5:179-89.
4. Alves JB, Gabani FL, Ferrari RA, Tacla MT, Linck Júnior A. Sepse neonatal: mortalidade em município do sul do Brasil, 2000 a 2013. Rev Paul Pediatr. 2018;36:132-40.

5. Shane AL, Sánchez PJ, Stoll BJ. Neonatal sepsis. Lancet. 2017;390:1770-80.

6. Zhao J, Kim KD, Yang X, Auh S, Fu YX, Tang H. Hyper innate responses in neonates lead to increased morbidity and mortality after infection. Proc Natl Acad Sci U S A. 2008;105:7528-33.

7. Silva AC, Gonçalves TM, Silva MD, Silva EL, Albuquerque MI, Oliveira MC, etal.Índice de morte neonatal precoce: uma análise do perfil materno. Rev Eletr Acervo Saude. 2019;26:e690.

8. França EB, Lansky S, Rego MA, Malta DC, França JS, Teixeira R, et al. Principais causas da mortalidade na infância no Brasil, em 1990 e 2015: estimativas do estudo de Carga Global de Doença. Rev Bras Epidemiol. 2017;20 Suppl 1:46-60.

9. Cavalcante FR, Cavalcante KK, Florencio CM, Moreno JO, Correia FG, Alencar CH. Human visceral leishmaniasis: epidemiological, temporal and spacial aspects in Northeast Brazil, 2003-2017. Rev Inst Med Trop Sao Paulo. 2020;62:e12.

10. Brasil. Ministério da Saúde. Fundação Nacional da Saúde. Manual de procedimento do sistema de informações sobre mortalidade. Brasília: Ministério da Saúde; 2001.

11. Brasil. Ministério da Saúde. ConselhoFederal de Medicina.Centro Brasileiro de Classificação de Doenças. A declaração de óbito: documento necessário e importante. $3^{\mathrm{a}}$ ed. Brasília: Ministério da Saúde; 2009. 
12. Goldstein B, Giroir B, Randolph A. International pediatric sepsis consensus conference: definitions for sepsis and organ dysfunction in pediatrics. Pediatr Crit Care Med. 2005;6:2-8

13. Rede Interagencial de Informação para a Saúde. Indicadores básicos para a saúde no Brasil: conceitos e aplicações. $2^{\mathrm{a}}$ ed. Brasília: Organização Pan-Americana da Saúde; 2008. [cited 2021 Mar 12]. Available from: http://tabnet.datasus.gov.br/tabdata/ livroidb/2ed/indicadores.pdf

14. Antunes JL, Cardoso MR. Uso da análise de séries temporais em estudos epidemiológicos. Epidemiol Serv Saude. 2015;24:56576.

15. Rudd KE, Johnson SC, Agesa KM, Shackelford KA, TsoiD, Kievlan $\mathrm{DR}$, et al. Global, regional, and national sepsis incidence and mortality, 1990-2017: analysis for the Global Burden of Disease Study. Lancet. 2020;395:200-11.

16. Weiss SL, Fitzgerald JC, Maffei FA, Kane JM, Rodriguez-Nunez A, Hsing DD, et al. Discordant identification of pediatric severe sepsis by research and clinical definitions in the SPROUT international point prevalence study. Crit Care. 2015;19:325

17. Weiss SL, Fitzgerald JC, Pappachan J, Wheeler D, JaramilloBustamante JC, Salloo A, et al. Global epidemiology of pediatric severe sepsis: the sepsis prevalence, outcomes, and therapies study. Am J Respir Crit Care Med. 2015;191:1147-57.

18. BoeddhaNP, SchlapbachLJ, Driessen GJ,Herberg JA, Rivero-Calle I, Cebey-López M, et al. Mortality and morbidity in communityacquired sepsis in European pediatric intensive care units: a prospective cohort study from the European Childhood Lifethreatening Infectious Disease Study (EUCLIDS). Crit Care. 2018;22:143.

19. MangiaCM, Kissoon N, Branchini OA, Andrade MC, Kopelman BI, Carcillo J. Bacterial sepsis in Brazilian children: a trend analysis from 1992 to 2006. PLoS One. 2011;6:e14817.

20. Claeson M, Gillespie D, Mshinda H, Troedsson H, Victora CG. Knowledge into action for child survival.Lancet. 2003;362:323 7.

21. United Nations General Assembly. Road map towards the implementation of the United Nations Millennium Declaration: report of the Secretary General. [cited 2021 Mar 12]. Available from: https://www.un.org/millenniumgoals/sgreport2001.pdf

22. Dellinger RP, Carlet JM, Masur H, Gerlach H, Calandra T, Cohen J, etal. Surviving Sepsis Campaign guidelines for management of severe sepsis and septic shock. Crit Care Med. 2004;30:536-55.

23. Dellinger RP, Levy MM, Carlet JM, Bion J, Parker MM, Jaeschke $\mathrm{R}$, et al. Surviving sepsis campaign: international guidelines for management of severe sepsis and septic shock: 2008. Crit Care Med. 2008;36:296-327.
24. Dellinger RP, Levy M, Rhodes A, Annane D, Gerlach H, Opal SM, et al. Surviving sepsis campaign: international guidelines for management of severe sepsis and septic shock: 2012. Intensive Care Med. 2013;39:165-228.

25. Rhodes A, Evans LE, Alhazzani W, Levy MM, Antonelli M, Ferrer $\mathrm{R}$, et al. Surviving Sepsis Campaign: International Guidelines for Management of Sepsis and Septic Shock: 2016. Crit Care Med. 2017;45:486-552.

26. Hartman ME, Linde-Zwirble WT, Angus DC, Watson RS. Trends in the epidemiology of pediatric severe sepsis. Pediatr Crit Care Med. 2013;14:686-93.

27. Schlapbach LJ, Straney L, Alexander J, MacLaren G, Festa M, Schibler A, et al. Mortality related to invasive infections, sepsis, and septic shock in critically ill children in Australia and New Zealand, 2002-13: a multicentre retrospective cohort study. Lancet Infect Dis. 2015; 15:46-54.

28. Elizeu MD, de Moura C, Catalan DT, Lima AB. Óbitos associados à sepses ocorridos no Hospital de Caridade São Vicente de Paulo em Jundiaí-SP, Brasil. J Heal Sci Inst. 2019;37:13-9.

29. Cardoso BB, Kale PL. Codificação da sepse pulmonar e o perfil de mortalidade no Rio de Janeiro, RJ. Rev Bras Epidemiol. 2016;19:609-20.

30. Instituto Latino-Americano para Estudos da Sepse. Sepse: um problema de saúde pública. Brasília: CFM; 2015. [cited 2021 Mar 12]. Available from: https://ilas.org.br/assets/arquivos/ upload/Livro-ILAS(Sepse-CFM-ILAS).pdf

31. Liang LD, Kotadia N, English L, Kissoon N, Mark Ansermino J, Kabakyenga J, et al. Predictors of mortality in neonates and infants hospitalized with sepsis or serious infections in developing countries: a systematic review. Front Pediatr. 2018;6:277.

32. SantosZ, OliveiraAP, Sales T. Sepse neonatal, avaliaçãodoimpacto: uma revisão integrativa. Bionorte. 2020;9:47-58.

33. Mukhopadhyay K, Louis D, Mahajan R, Kumar P. Predictors of mortality and major morbidities in extremely low birth weight neonates. Indian Pediatr. 2013;50:1119-23.

34. Freitas CB, Teixeira GM, Lana PD, Zopelaro RB, Pinto ES. Sepse neonatal: fatores de risco associados. Rev Cien Univiçosa. 2016;8:883-9.

35. Yu JC, Khodadadi H, Malik A, Davidson B, Salles ES, Bhatia J, et al. Innate immunity of neonates and infants. Front Immunol. 2018;9:1759.

36. Cunha CC, Teixeira R, França E. Avaliação da investigação de óbitos por causas mal definidas no Brasil em 2010. Epidemiol Serv Saude. 2017;26:19-30. 